\title{
Functional impact and targetability of PI3KCA, GNAS, and PTEN mutations in a spindle cell rhabdomyosarcoma with MYOD1 L122R mutation
}

\author{
Florence Choo, ${ }^{1}$ Igor Odintsov, ${ }^{2,3}$ Kevin Nusser, ${ }^{1}$ Katelyn S. Nicholson, ${ }^{1}$ \\ Lara Davis, ${ }^{4}$ Christopher L. Corless, ${ }^{5}$ Linda Stork, ${ }^{1}$ Romel Somwar, ${ }^{2,3}$ \\ Marc Ladanyi, ${ }^{2,3}$ Jessica L. Davis, ${ }^{5}$ and Monika A. Davare ${ }^{1}$
}

\begin{abstract}
${ }^{1}$ Division of Pediatric Hematology/Oncology, Department of Pediatrics, Oregon Health and Science University (OHSU), Portland, Oregon 97239, USA; ${ }^{2}$ Department of Pathology, ${ }^{3}$ Human Oncology and Pathogenesis Program, Memorial Sloan Kettering Cancer Center, New York, New York 10065, USA; ${ }^{4}$ Knight Cancer Institute, Division of Hematology/Oncology, ${ }^{5}$ Knight Cancer Institute and Department of Pathology, OHSU, Portland, Oregon 97239, USA
\end{abstract}

Corresponding author: davarem@ohsu.edu

(c) 2022 Choo et al. This article is distributed under the terms of the Creative Commons Attribution-NonCommercial License, which permits reuse and redistribution, except for commercial purposes, provided that the original author and source are credited.

\section{Ontology term:}

rhabdomyosarcoma

Published by Cold Spring Harbor Laboratory Press

doi:10.1101/mcs.a006140
Abstract Spindle cell/sclerosing rhabdomyosarcoma (ssRMS) is a rare subtype of rhabdomyosarcoma, commonly harboring a gain-of-function L122R mutation in the muscle-specific master transcription factor MYOD1. MYOD1-mutated ssRMS is almost invariably fatal, and development of novel therapeutic approaches based on the biology of the disease is urgently needed. MYOD1 L122R affects the DNA-binding domain and is believed to confer MYC-like properties to MYOD1, driving oncogenesis. Moreover, the majority of the MYOD1-mutated ssRMS harbor additional alterations activating the PI3K/AKT pathway. It is postulated that the PI3K/AKT pathway cooperates with MYOD1 L122R. To address this biological entity, we established and characterized a new patient-derived ssRMS cell line OHSU-SARC001, harboring MYOD1 L122R as well as alterations in PTEN, PIK3CA, and GNAS. We explored the functional impact of these aberrations on oncogenic signaling with gain-of-function experiments in C2C12 murine muscle lineage cells. These data reveal that PIK3CA ${ }^{1459-T 462 d e l}$, the novel PIK3CA variant discovered in this patient specimen, is a constitutively active kinase, albeit to a lesser extent than PI3KCA ${ }^{\mathrm{E} 545 \mathrm{~K}}$, a hotspot oncogenic mutation. Furthermore, we examined the effectiveness of molecularly targeted PI3K/AKT/mTOR and RAS/MAPK inhibitors to block oncogenic signaling and suppress the growth of OHSU-SARC001 cells. Dual PI3K/mTOR (LY3023414, bimiralisib) and AKT inhibitors (ipatasertib, afuresertib) induced dose-dependent reductions in cell growth. However, mTOR-selective inhibitors (everolimus, rapamycin) alone did not exert cytotoxic effects. The MEK1/2 inhibitor trametinib did not impact proliferation even at the highest doses tested. Our data suggest that molecularly targeted strategies may be effective in PI3K/AKT/mTOR-activated ssRMS. Taken together, these data highlight the importance of utilizing patient-derived models to assess molecularly targetable treatments and their potential as future treatment options.

[Supplemental material is available for this article.]

\section{INTRODUCTION}

Rhabdomyosarcoma (RMS) is a malignant soft-tissue tumor arising from primitive mesenchymal cells of striated muscle lineage. It is the most common soft-tissue sarcoma in children 
and adolescents, comprising 3\% of all pediatric tumors (Amer et al. 2019) and 40\% of all pediatric soft-tissue sarcomas (Ognjanovic et al. 2009). Genomic and histologic advances have shaped the evolving understanding of RMS that has been historically classified based on histology. The most recently updated fifth edition of the Soft Tissue and Bone Tumours: WHO Classification of Tumours (World Health Organization 2020) includes four histologic categories of RMS: embryonal (including botryoid), alveolar, spindle cell/sclerosing (ssRMS), and pleomorphic. ssRMS is a rare, recently recognized subtype of RMS and accounts for $3 \%-10 \%$ of pediatric RMS (Newton et al. 1995; Jo and Fletcher 2014). In the latest, fifth edition of the WHO Classification, ssRMS encompasses a heterogeneous group of tumors with distinct clinicopathologic and genetic subtypes of ssRMS, including three genetically defined subtypes of ssRMS (Leuschner et al. 1993; Rudzinski et al. 2015). The genetic subtypes of ssRMS include infantile ssRMS, intraosseous ssRMS, and MYOD1-mutated ssRMS. Infantile ssRMS harbors recurrent gene fusions involving VGLL2 and NCOA2 (Cavazzana et al. 1992; Cyrta et al. 2021). These tumors were initially thought to have a favorable prognosis; however, recent evidence shows the potential for late metastases and potentially death from disease (Cyrta et al. 2021). Rare and recently described intraosseous ssRMS with TFPC2 gene fusions are also associated with a poor prognosis, although only limited data are available. MYOD1-mutated ssRMS is most common in adolescents and adults in the head and neck region (particularly parameningeal) and associated with a poor prognosis. Recurrence and metastasis have been reported in $40 \%-50 \%$ of cases and death from disease in $50 \%-80 \%$ of patients (Agaram et al. 2019).

MYOD1 encodes a basic helix-loop-helix transcription factor that is a master regulator of skeletal muscle differentiation (Sorrentino et al. 1990; Maione and Amati 1997; Weintraub 1993). Another member of the basic helix-loop-helix transcription factors family, MYC, possesses a similar DNA binding domain. MYOD1 L122R alters the DNA binding domain, permitting binding to MYC sites. Moreover, based on functional assays, MYOD1 L122R competes for DNA binding sites with wild-type (WT) MYOD1, thereby inhibiting differentiation and sustaining proliferation (Van Antwerp et al. 1992). Investigations of muscle cell differentiation assessed by immunofluorescence and soft agar colony formation assays support the hypothesis that MYOD1 L122R hinders differentiation and promotes proliferation (Kohsaka et al. 2014). Clinically, MYOD1 L122R is a poor prognostic marker, and outcomes in patients with MYOD1 L122R are dismal compared to WT MYOD1 (10-yr overall survival [OS] of $0 \%$ in MYOD1 L122R vs. 48\% in WT MYOD1 ssRMS patients) (Kohsaka et al. 2014). One of the largest genomic studies of RMS, combining results of clinical trials from the Children's Oncology Group (COG) and Intergroup Rhabdomyosarcoma Study Group (IRSG) (ARST0331, ARST0431, D9602, D9803, D9902; 1998-2017), also found that outcomes are worse in MYOD1 L122R versus WT MYOD1 cases (Shern et al. 2021). Poor outcomes within this subtype highlight the need to better understand RMS tumor biology and to investigate new approaches to therapy.

Concomitant mutations in the PI3K/AKT pathway have been identified in MYOD1-mutated ssRMS. PIK3CA hotspot mutations in the helical (E542K, E542V, E545K) or kinase (H1047R) domain are present in $40 \%$ of these tumors (Kohsaka et al. 2014; Agaram et al. 2019; Tsai et al. 2019; Shern et al. 2021), whereas PTEN mutations are observed in 6\%7\% of cases (Agaram et al. 2019; Shern et al. 2021). Prior functional investigations reveal that PI3K/AKT pathway cooperates with MYOD1 L122R in model systems (Kohsaka et al. 2014). Thus, targeting the PI3K/AKT pathway represents a promising, but underexplored, strategy to therapeutically target MYOD1-mutated ssRMS.

Here, we established a new patient-derived xenograft (PDX) and a cell line OHSUSARC001 from a patient with spindle cell RMS. In addition to MYOD1 L122R and PTEN ${ }^{\text {R173H }}$ mutations, the tumor harbored subclonal PIK3CA ${ }^{\text {1459_T462del }}$ and GNAS ${ }^{\text {R201C }}$ mutations. The xenograft and cell line provided an opportunity to explore the effectiveness of 
inhibitors targeting the PI3K/AKT/mTOR and RAS/MAPK pathways in the setting of MYOD1mutated ssRMS.

\section{RESULTS}

\section{Clinical Presentation}

A previously healthy 15 -yr-old male presented with a right nasal mass that progressively enlarged over a period of several weeks (Fig. 1A). There was no family history of childhood malignancies. Staging and diagnostic workup included a maxillofacial computed tomography (CT) that demonstrated a $2.3 \times 4.1 \times 3.0-\mathrm{cm}$ enhancing soft-tissue mass with bony remodeling without destructive changes (Fig. 1B), and a baseline facial and neck magnetic resonance imaging (MRI) that confirmed a $3.2 \times 3.1 \times 3.1-\mathrm{cm}$ enhancing, multilobulated right nasal mass. Histological analysis of an intranasal biopsy demonstrated intersecting fascicles of spindle cells that filled the dermis and subcutis. Individual tumor cells had elongated to tapered nuclei and eosinophilic cytoplasm. The presence of relatively prominent
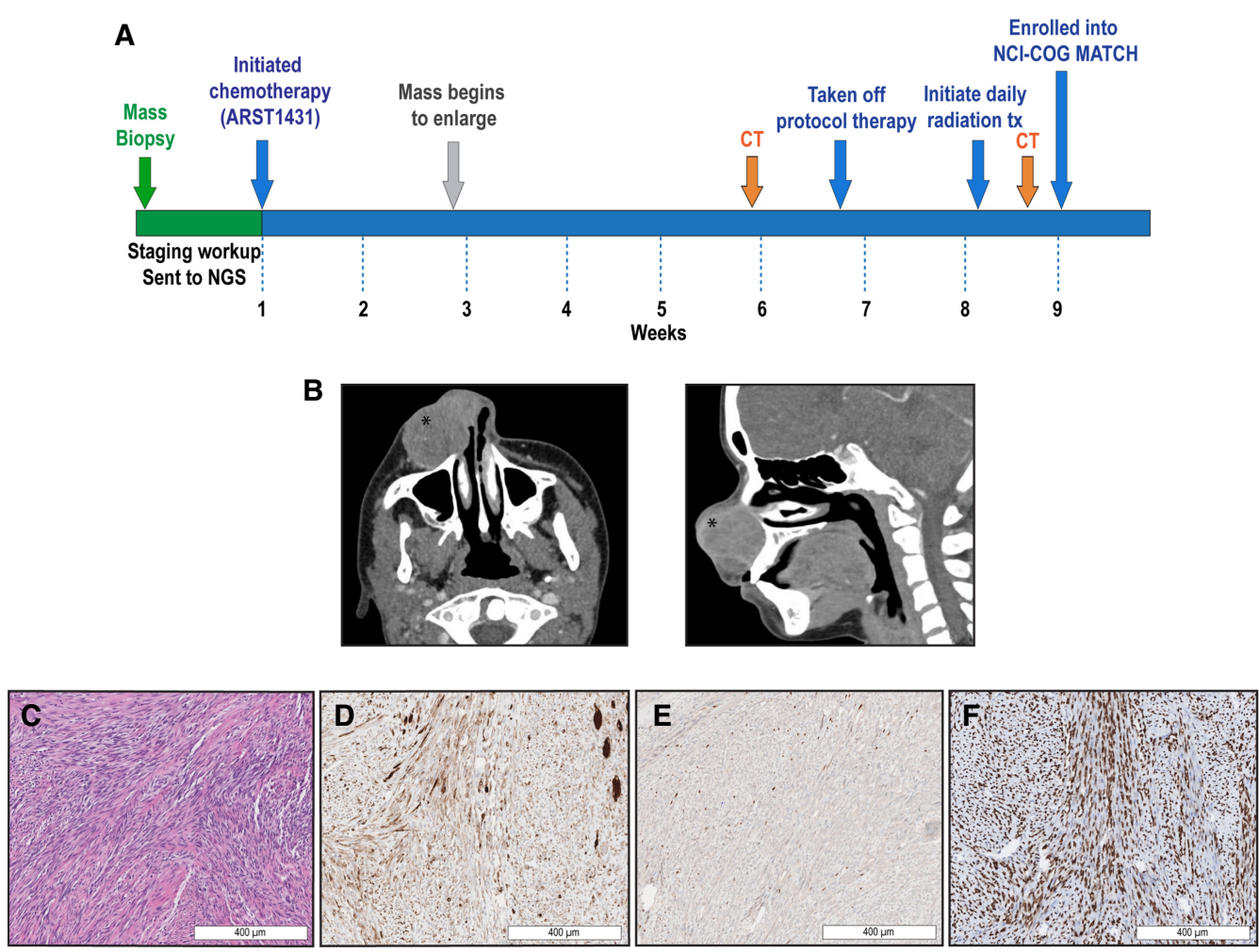

Figure 1. Patient presentation, clinical course, and pathologic evaluation. (A) Clinical course from initial presentation, refractory disease, and resection of the tumor. The patient underwent initial workup involving imaging, biopsy, and next-generation sequencing (NGS) via GeneTrails Comprehensive Solid Tumor Panel. He was treated on Children's Oncology Group (COG) ARST1431 until he had refractory disease. At the time of resection, the patient enrolled in the National Cancer Institute (NCl)-COG MATCH trial. (B) Initial diagnostic maxillofacial computed tomography (CT) identified a $2.3 \times 4.1 \times 3.0-\mathrm{cm}$ enhancing soft-tissue mass (as noted with *) with bony remodeling without destructive changes. (C) Diagnostic biopsy showed intersecting spindle cells with elongated, tapered nuclei and prominent rhabdomyoblasts and strap cells on hematoxylin and eosin (H\&E). (D) Desmin staining showed patchy cytoplasmic expression. (E) Myogenin exhibited punctate nuclear expression. (F) MYOD1 nuclear expression was strong and diffuse. 
rhabdomyoblasts and strap cells was consistent with rhabdomyoblastic differentiation (Fig. 1C). The tumor had patchy cytoplasmic expression for desmin (Fig. 1D), punctate nuclear expression of myogenin (Fig. 1E), strong diffuse nuclear expression of MYOD1 (Fig. 1F), and lacked S100 on immunohistochemical staining (Supplemental Table 1). Together, these findings supported the diagnosis of ssRMS. At the time of the intranasal biopsy, next-generation sequencing (NGS) using the Clinical Laboratory Improvement Amendments (CLIA)-certified GeneTrails Solid Tumor panel (Mitri et al. 2018) on a formalin-fixed paraffin-embedded (FFPE) sample confirmed a MYOD1 L122R mutation and showed CDKN2A copy loss, FAM175A ${ }^{\text {D352N }}$, GNAS ${ }^{\text {R201C }}$, PIK3CA ${ }^{1459-T 462 d e l}$, PTEN $^{\text {R173H }}$, and RAD50 R1279H (Table 1).

Based on the patient's clinical workup, the tumor was classified as IRSG III (parameningeal), TNM stage 2 (T1NOM0). He enrolled onto COG ARST1431 (NCT02567435), a randomized phase three trial for patients with intermediate risk RMS and was randomized to standard chemotherapy with vincristine, dactinomycin, cyclophosphamide, and irinotecan. However, his mass rapidly enlarged by the end of week 2 of treatment, and a CT demonstrated a $5.6 \times 4.4 \times 4.8-\mathrm{cm}$ mass with new cortical erosion along the right maxilla and periosteal reaction. The patient was removed from protocol therapy (Fig. 1A) as a result of progressive growth (per Response Evaluation Criteria in Solid Tumors [RECIST] criteria of $\geq 20 \%$ increase in the sum of diameters and an absolute increase of at least $5 \mathrm{~mm}$ ). Despite initiation of daily radiation treatments (total dose of $720 \mathrm{cGy}$ ), the tumor continued to progress, at which point the patient underwent radical resection of the right nasal and facial tumor. Prior to resection, he was enrolled onto the Pediatric MATCH screening trial (NCT03155620) in which an NGS

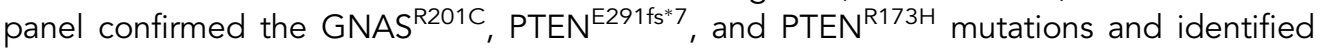
LY3023414 as a targeted treatment option (Table 1).

Prior to the radical resection of the right nasal tumor, the patient consented to donate tissue to the Knight BioLibrary Research Repository approved by OHSU's Institutional Review Board (IRB), enabling the establishment of a pediatric-derived ssRMS cell line with unique molecularly actionable targets. OHSU-SARC001 represents one of the few established patient-derived ssRMS cell lines and is the first pediatric MYOD1-mutated ssRMS cell line with concomitant mutations in PIK3CA and GNAS available for preclinical investigations.

Postoperatively, the patient completed $41.4 \mathrm{~Gy}$ in 23 fractions of consolidative radiotherapy and began salvage chemotherapy with ifosfamide and etoposide. Six weeks after radiation, he received alternating ifosfamide and etoposide with ifosfamide and doxorubicin for a total of eight courses. He continued with ARST1431 maintenance treatment with vinorelbine and oral cyclophosphamide. At the time of this writing, he is more than a year out from treatment and is currently alive with no signs of recurrence.

\section{Creation and Validation of a Patient-Derived Spindle Cell Rhabdomyosarcoma Cell Line and Testing Tumorigenic Potential Using a Mouse Model}

The OHSU-SARC001 cell line was established as an outgrowth from the primary resected tumor sample. Phase-contrast microscopy imaging (10x) of the OHSU-SARC001 monolayer culture showed spindle-like morphology and focal aggregations of tumor cells (Fig. 2A). To confirm retention of molecular aberrations noted in the patient's primary tumor, we repeated GeneTrails Solid Tumor panel on DNA from the established OHSU-SARC001 cell line. Results showed conservation of the genomic aberrations identified in the diagnostic specimen (Table 1) and an additional variant of unknown significance involving ROS1. Notably, PIK3CA ${ }^{1459}$ _T462del and GNAS ${ }^{\text {R201C }}$ were present with allele fractions of $22 \%$ and $48 \%$, respectively. Although FAM175A and MYOD1 were listed as detected on the GeneTrails assay, notably these genes were not tested as a part of the NCl-COG MATCH NGS panel. Although the frameshift PTEN mutation was detected in NCl-COG MATCH and OHSU-SARC001, it was not in the diagnostic sample. Differences in methodology 


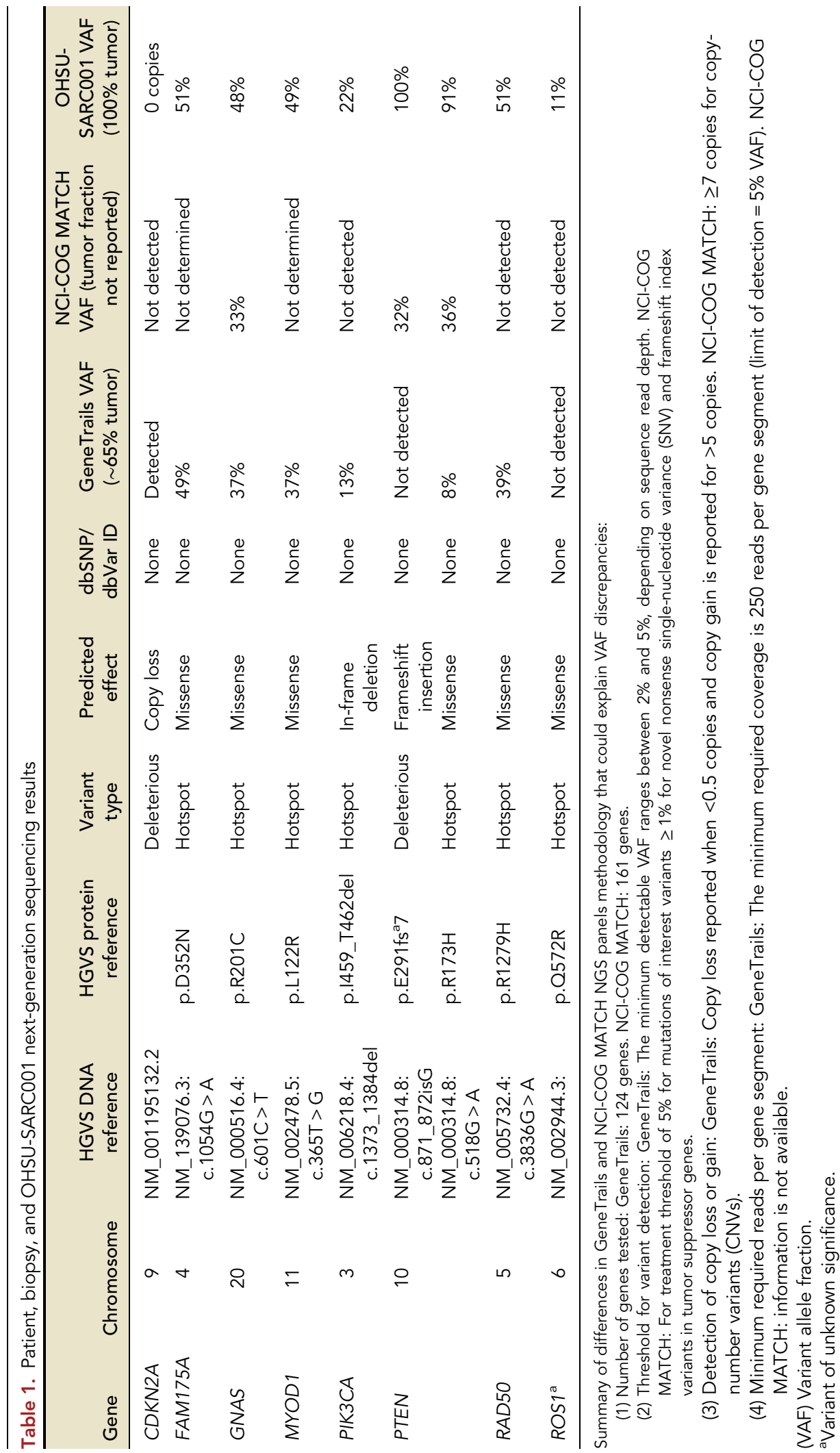



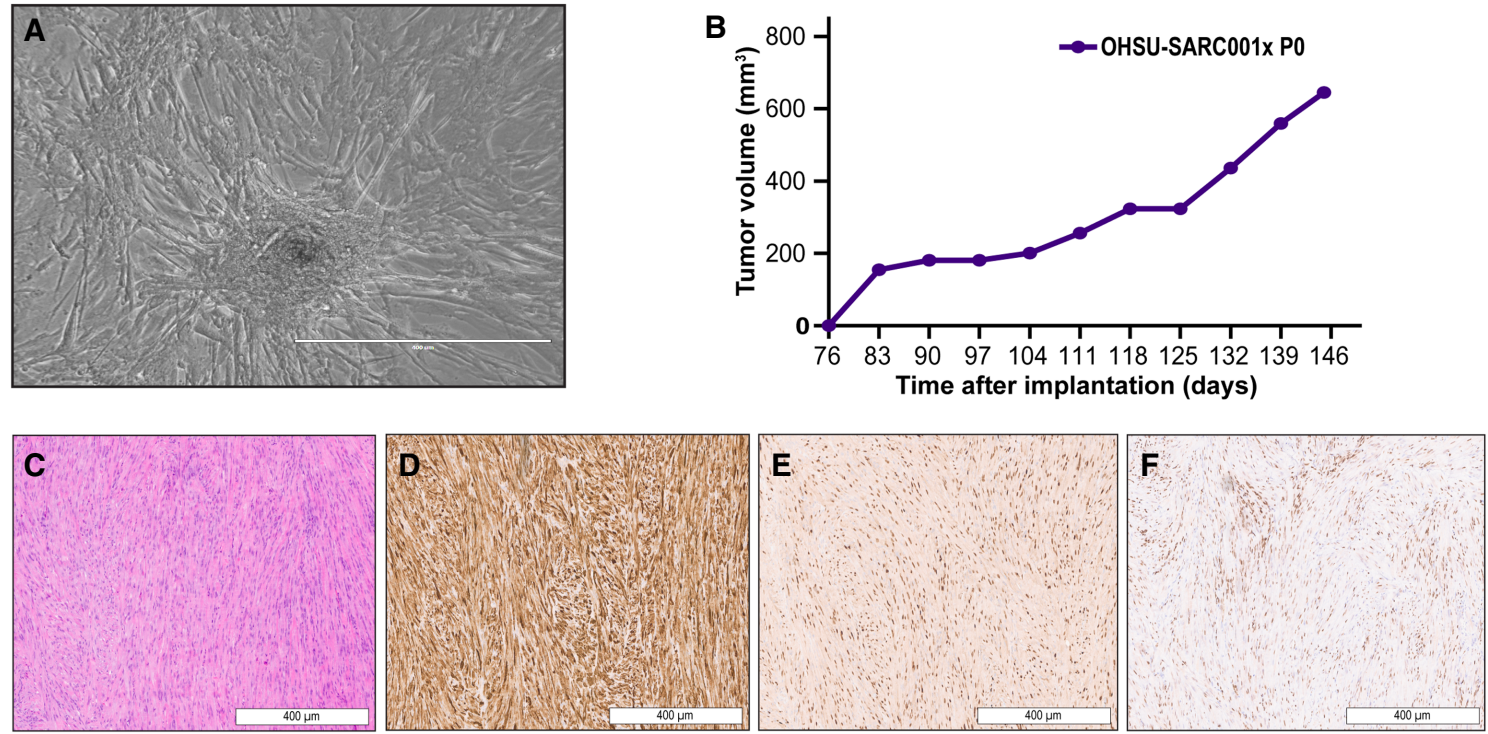

Figure 2. In vitro, in vivo, and pathologic characterization of OHSU-SARC001. (A) Phase contrast imaging $(10 \times)$ demonstrates spindle-shaped morphology and a focal collection of tumor cells. (B) Patient-derived xenograft (PDX) tumors were grown in NOD scid gamma (NSG) mice (PO). An increase in tumor volume $\left(\mathrm{mm}^{3}\right)$ was initially measured starting at day 76 and was monitored over time until the tumor was transplanted at day 146. (C) PDX hematoxylin and eosin (H\&E) staining revealed elongated spindle cells in fascicular arrangement. (D) Desmin was strongly diffuse. (E) Strong nuclear expression of mygoenin was present. (F) MYOD1 expression showed patchy nuclear expression.

and tumor purity may account for some discordance between the sequencing results from the diagnostic, NCl-COG MATCH, and OHSU-SARC001 NGS panels. To test the tumorigenic potential of the OHSU-SARC001 cell line, cells were injected into a subcutaneous flank of female NOD scid gamma (NSG) mice. Palpable tumors were noted $76 \mathrm{~d}$ after implantation (Fig. 2B) and the xenograft tumor was transplanted on day 146 when it was of $645 \mathrm{~mm}^{3}$ volume. Hematoxylin and eosin (H\&E) stains and immunohistochemistry were performed on formalin-fixed paraffin-embedded (FFPE) slides generated from the xenograft tumor in order to compare the histology to the primary tumor. The H\&E-stained sample demonstrated relatively uniform elongated spindle cells arranged in fascicles (Fig. 2C). The individual tumor cells showed ovoid nuclei and a moderate amount of eosinophilic cytoplasm. No overt rhabdomyoblastic differentiation (including rhabdomyoblasts or strap cells) was present. Immunohistochemical staining demonstrated strong, diffuse desmin expression (Fig. 2D), nuclear expression of myogenin ( $>50 \%$ of cells) (Fig. 2E), and patchy nuclear expression for MYOD1 (Fig. 2F). In comparison to the original tumor, MYOD1 expression was less diffuse and myogenin expression was increased in the xenograft tumor. Overall, the morphology, immunophenotype, and sequencing support the conservation of the primary tumor characteristics in the patient-derived xenograft tumor.

\section{Characterizing Impact of PI3K, GNAS, and PTEN Mutations on Signaling Pathway Activation and Cellular Functions}

The novel PIK3CA ${ }^{1459}$ T462del mutation is located within exon 9, a known hotspot of PI3KCA oncogenic mutations in cancer (Zhang et al. 2017). Notably, both exon 9 (e.g., PI3KCA ${ }^{\mathrm{E} 45 \mathrm{~K} \text { ) }}$ and exon 20 (e.g., PI3KCA ${ }^{\mathrm{H} 1047 \mathrm{R}}$ ) PI3KCA mutations have been previously identified in 
spindle cell rhabdomyosarcoma (Kikuchi et al. 2013; Kohsaka et al. 2014; Agaram et al. 2019; Tsai et al. 2019), suggesting a potential role of this pathway in the pathogenesis of MYOD1mutated ssRMS. We mapped the location of this novel PI3KCA ${ }^{1459-T 462 d e l}$ mutation, in reference to the known PI3KCA ${ }^{\mathrm{E5} 45 \mathrm{~K}}$ oncogenic substitution, onto the crystal structure of PIK3CA (Protein Data Bank ID: 2RD0) and found that the PIK3CA ${ }^{\text {1459_T462del }}$ aberration resides within the interface of the protein that interacts with the PI3K regulatory subunit, p85 (Fig. 3A; as a reference, $\mathrm{PI} 3 \mathrm{KCA}^{\mathrm{E5} 45 \mathrm{~K}}$ is shown in yellow). The p85 regulatory subunit stabilizes the p110 catalytic subunit and prevents autonomous activity. Based on its location, the PIK3CA ${ }^{1459-T 462 d e l}$ mutation may reduce affinity or negatively affect the interaction of p110 with the p85 regulatory subunit, allowing constitutive catalytic activation in the absence of the regulatory subunit.

We tested the impact of the PIK3CA ${ }^{1459-T 462 d e l}$ mutation on the activation of mTOR/AKT pathway and RAS/MAPK pathway by retroviral transduction of the murine myoblast cell line, C2C12, with wild-type and mutant CDNAs. The C2C12 cell line was chosen based on the well-established record of this model system for functional interrogation of molecular mechanisms involved in muscle differentiation, the activity of putative oncogenic driver genes associated with sarcoma, and pharmacological strategies to block tumorigenic pathways (Owens et al. 2013; Kohsaka et al. 2014). Stable cell lines were validated via Sanger sequencing (Supplemental Fig. 1). Immunoblotting data (Fig. 3B) showed that expression of PIK3CA ${ }^{1459-T 462 d e l}$ activates Akt (pAkt ${ }^{\mathrm{T308}}$ and $\mathrm{pAkt}^{\mathrm{S} 473}$ ) and mTOR pathway effectors Tsc2 $\left(p^{T s c}{ }^{T 1462}\right), p 70 s 6 k\left(p 70 s 6 k^{T 389}\right), S 6\left(p 56^{\mathrm{S} 235 / 236}\right)$, and 4ebp1 (p4ebp1 ${ }^{T 37 / 46)}$, as well as

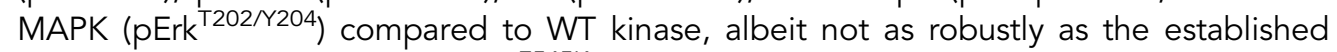
PI3KCA hotspot mutation, PI3KCA ${ }^{E 545 K}$.

Guanine nucleotide-binding proteins ( $G$ proteins) transduce signals from numerous signaling pathways through their GTPase activity. The Gs a-subunit encoded by GNAS is a G protein that activates adenylyl cyclase, generating cyclic AMP (cAMP), a small molecule mediator of various downstream pathways. GNAS ${ }^{\text {R201C }}$ is a gain-of-function mutation promoting activity of Gs alpha subunit and cooperates with APC aberrations in colorectal tumorigenesis (Wilson et al. 2010). A previous publication suggests that cAMP (via RAP1 and RAP1B) can activate or inhibit the MAPK pathway in a cell lineage-specific manner and is dependent on the status of B-Raf expression. In B-Raf-negative cells, RAP1 inhibits RAS and therefore the Raf-1/MEK/ERK pathway. Conversely, in B-Raf-positive cells such as C2C12 murine myoblasts, RAP1 activates B-Raf and therefore the MEK/ERK pathway (Stork and Schmitt 2002). Thus, the expression of downstream effectors dictates whether GNAS activates the RAS/MEK/ERK pathway. Because the role of GNAS ${ }^{\mathrm{R} 102 \mathrm{C}}$ is unexplored in ssRMS, we examined whether the Raf-1/MEK/ERK pathway is activated in muscle lineage cells. When expressed in C2C12 murine myoblasts, GNAS ${ }^{\mathrm{R} 201 \mathrm{C}}$ did not activate the MAPK pathway as compared to wild-type GNAS (Fig. 3B). Given the lack of activation noted in GNAS $^{\text {R201C }}$, we probed for RAP1, B-Raf, and C-Raf as the expression of these effectors is required to support of MEK/ERK pathway activation downstream from GNAS. Interestingly, RAP1B, B-Raf, and C-Raf are expressed in OHSU-SARC001 (Fig. 3C). These data indicate that although the signaling components to activate MEK/ERK downstream from GNAS $^{\text {R201C }}$ are present in C2C12 cells, this alteration alone is insufficient to activate the MEK/ERK pathway. Thus, GNAS ${ }^{\text {R201C }}$ alone may not be a dominant driver pathway amenable for therapeutic intervention.

Finally, given the identification of the frameshift mutation PTEN ${ }^{E 291 \mathrm{fs}^{* 7}}$ in OHSUSARC001, we tested PTEN expression and found that full-length PTEN is undetectable. C2C12 cells were used as a positive control (Fig. 3C). Frameshift mutations in PTEN may lead to nonsense mediated decay of the mutant mRNA or potentially lead to the expression of a truncated protein that lacks the epitope required for detection by the antibody (epitope is not revealed by the commercial source of this antibody). 
A

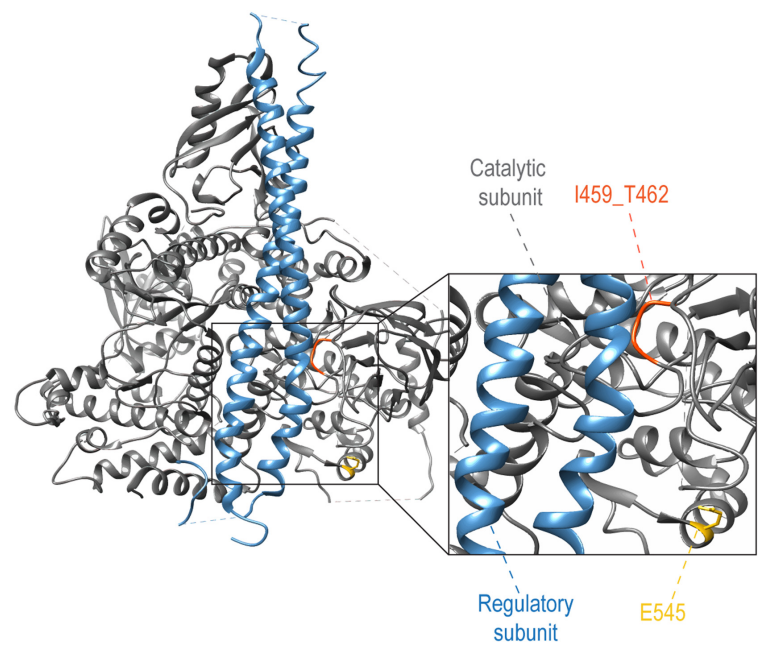

C

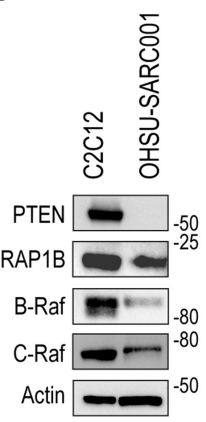

D
B
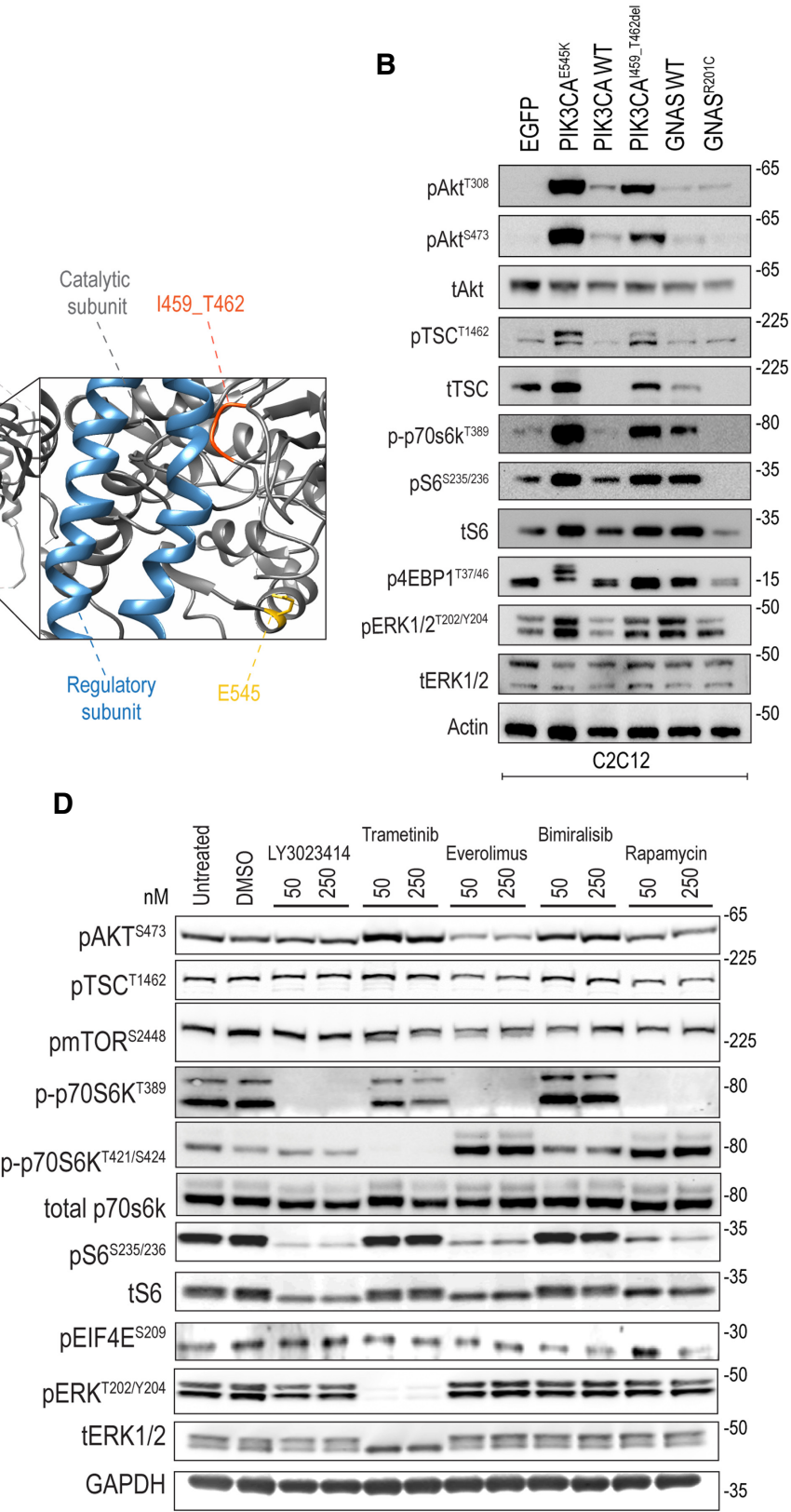

Figure 3. Crystal structure rendering of PIK3CA ${ }^{1459-T 462 d e l}$ and expression of $m T O R / A K T$ and MAPK signaling pathways in transduced C2C12 cell lines, OHSU-SARC001, and after molecularly targeted kinase inhibitors. (A) PIK3CA ${ }^{1459}$ T462del interfaces with the regulatory PIK3CA subunit and may disrupt the interaction between PI3K catalytic and regulatory subunits to induce catalytic activation. (B) C2C12 stable cell lines harboring wild-type and mutant CDNA suggest that PIK3CA ${ }^{1459}{ }^{T 462 d e l}$ modestly activates pAkt ${ }^{\text {T308 }}$, pAkt ${ }^{\text {S473 }}$, pTsc $^{\text {T1462 }}$, p70s6k ${ }^{T 389}, \mathrm{pS}^{\mathrm{S} 235 / 236}, \mathrm{p} 4 \mathrm{ebp}-1^{\mathrm{T} 37 / 46}$, and pEerk ${ }^{\mathrm{T} 202 / \text { 204 }}$ compared to WT PIK3CA. Of note, 4EBP1 undergoes sequential hyperphosphorylation on Thr37 and Thr46, followed by up to six residues in the carboxyl terminus. This increase in 4EBP1 phosphorylation decreases its electrophoretic mobility. GNAS ${ }^{R 201 C}$ does not appear to activate the mTOR/Akt or MAPK pathway compared to WT GNAS. (C) OHSU-SARC001 has PTEN loss and expresses RAP1B, B-Raf, and C-Raf. (D) In OHSU-SARC001, phosphorylation of downstream mTOR/AKT signal effectors $\mathrm{p} 70 \mathrm{~S} 6 \mathrm{~K}^{\mathrm{T} 389}$ and $\mathrm{pS} 6^{\mathrm{S} 235 / 236}$ was decreased when exposed to LY3023414, everolimus, and rapamycin. Effectors $\mathrm{p} 70 \mathrm{~S} 6 \mathrm{~K}^{\mathrm{T} 421 / \mathrm{S} 424}$ were decreased in trametinib-treated cells. Trametinib treatment resulted in decreased expression of pERK ${ }^{\mathrm{T} 202 / \text { T2 }^{204}}$. 
COLD SPRING HARBOR Molecular Case Studies
Targeted agents in spindle cell rhabdomyosarcoma
Molecularly Targeted Kinase Inhibitors Have On-Target Effects on PI3K and MAPK Pathway Protein Phosphorylation

To investigate activity of molecularly targetable agents, OHSU-SARC001 was first treated with inhibitors targeting mTOR/PIK3CA (LY3023414, identified in the NCl-COG MATCH trial, and bimiralisib), mTOR alone (everolimus and rapamycin), or MEK (trametinib) (Fig. 3D) at 50- and 250-nM concentrations for biochemical analysis. Immunoblotting with phosphospecific antibodies shows on-target effects on the mTOR/AKT and MAPK signaling pathway. Phosphorylation of the downstream mTOR/AKT signal effectors p70S6K and pS6 (S235/236) is inhibited by LY3023414 (PI3K/mTOR), everolimus (mTOR), and rapamycin (mTOR). p70S6K has at least seven possible phosphorylation sites, including T389 in the linker domain, which is critical for kinase function and S411, T421, and S424 that lie within the serine-proline-rich pseudosubstrate region. As seen in the LY3023414, rapamycin, and everolimus-treated lanes, the PI3K/mTOR kinase pathway governs phosphorylation of the critical T389 site in p70S6K. Intriguingly, immunoblotting with antibody directed to phosphorylated T421/S424 in p70S6K reveals that the MEK/ERK but not the PI3K/mTOR pathway is responsible for T421/S424 phosphorylation, as seen by loss of signal in trametinib-treated cells, but not with LY3023414, rapamycin, or everolimus. These data suggest that both PI3K/ mTOR and MEK/ERK converge onto p70S6K via different phosphorylation site usage. As expected, phosphorylation of ERK (T202/Y204) was decreased in trametinib-treated cells (Fig. 3D). Bimiralisib, a dual PI3K/mTOR inhibitor, did not perform as expected where we see no impact of this inhibitor on phospho-activation of p70S6K or S6. It is possible that we did not use sufficient inhibitor concentration to achieve the desired effect and may have needed a $>250-n M$ inhibitor. Alternatively, the stated purity or potency of this inhibitor from a commercial source may not have been accurate; thus, again, it would have required us to use more inhibitor than hypothesized.

\section{OHSU-SARC001 Cells Are Sensitive to Dual PIK3CA and AKT Inhibitors}

We interrogated the effect of targeted mTOR (rapamycin and everolimus), dual PI3K/mTOR (LY3023414 and bimiralisib), AKT (ipatasertib and afuresertib), and MEK1/2 (trametinib) inhibitors using dose-response cell viability assays. These data revealed that everolimus and rapamycin block cell growth (Fig. 4A) but do not induce cell death. In comparison, dual mTOR/PIK3CA inhibitors, LY3023414 and bimiralisib, as well as AKT inhibitors, ipatasertib and afuresertib, exhibit dose-dependent cytotoxic effects (Fig. 4B,C). Trametinib was ineffective in cell viability studies up to $5-\mu \mathrm{M}$ inhibitor concentration (Fig. 4D), despite achieving near-complete abrogation of ERK1/2 phosphorylation with 50-nM concentration, as detected by immunoblotting (Fig. 3D). These data suggest that MEK/ERK alone is not a targetable vulnerability in OHSU-SARCO01.

In a complementary experiment (Fig. 4E,F), we tested growth-inhibitory effects of these inhibitors at static doses and measured percent cell viability (normalized to control). These data showed that LY3023414 at 50 and $250 \mathrm{nM}$ strongly suppressed cell growth, whereas a higher concentration of the AKT inhibitor afuresertib $(250 \mathrm{nM})$ was needed to achieve the same effect. Cells treated with rapamycin and everolimus fail to exhibit growth or death; we hypothesize that the cells are in some state of quiescence and the cell viability reagent detects the number of cells plated at seeding density (Fig. 4A,E,F). Consistent with dose-response cell viability data, trametinib treatment was ineffective in OHSU-SARC001 cells (Fig. $4 \mathrm{E})$. At the static doses tested, bimiralisib was ineffective, and these data are consistent with the failure of these doses to inhibit target pathway protein activation (Fig. 3D) at these concentrations and with data from dose-response assays that show $I_{50}=680 \mathrm{nM}$, well above the $250 \mathrm{nM}$ dose tested here. 
A

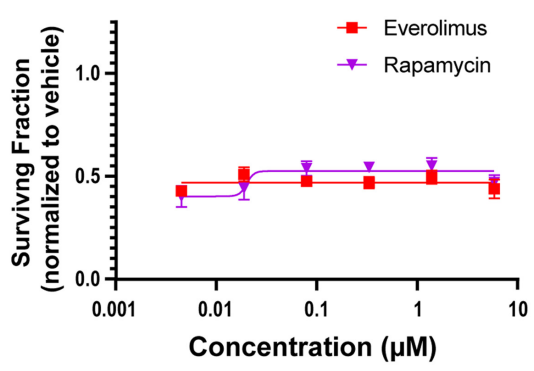

C

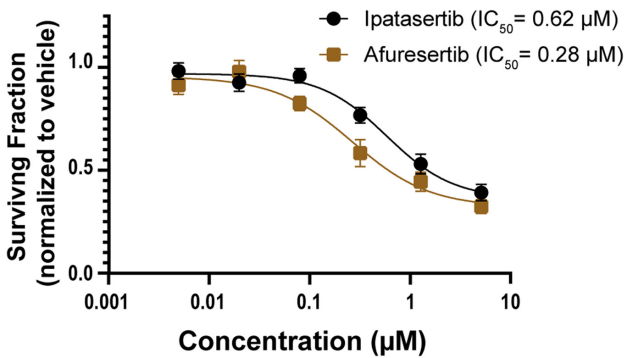

E

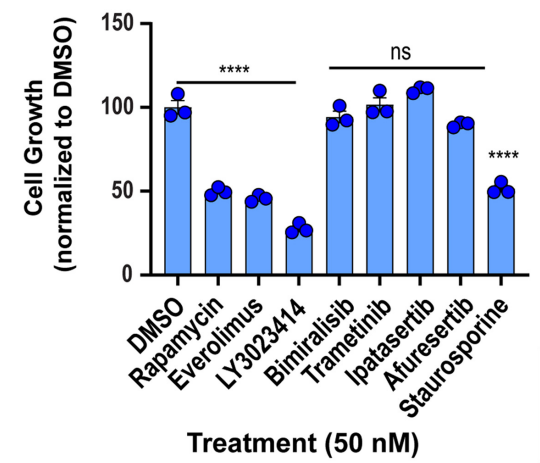

B

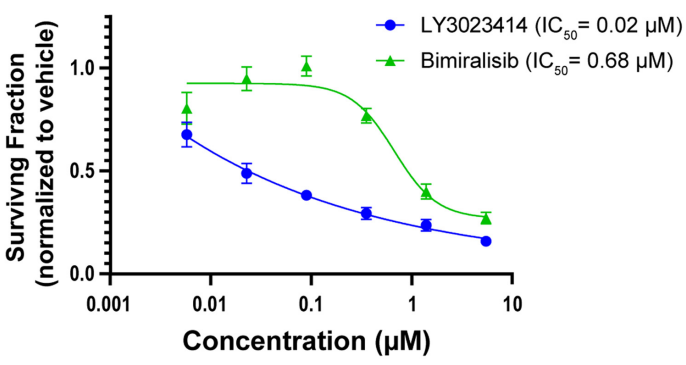

D

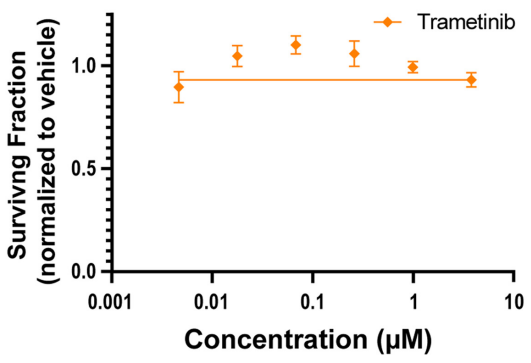

$\mathbf{F}$

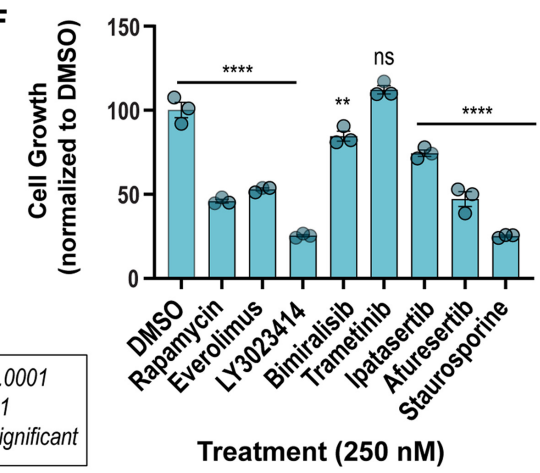

Figure 4. Cell viability assays reveal cytotoxic effect of select molecularly targeted inhibitors in OHSUSARC001 cells. (A-D) Dose-response cell viability assay data from the testing of (A) mTOR inhibitors, everolimus, and rapamycin, (B) dual PI3K/mTOR inhibitors, LY3023414 and bimiralisib, (C) pan-AKT inhibitors, ipatasertib and afuresertib, and (D) MEK1/2 inhibitor, trametinib. A nonlinear regression curve fit algorithm was unstable and for everolimus, $R^{2}=0$; rapamycin, $R^{2}=0.16$; and trametinib, $R^{2}=-0.22$. Therefore, these data are not included. $(E, F)$ Cell viability data from static dose testing of indicated inhibitors at 50 and 250 nM concentration, respectively. Statistical analysis with two-way ANOVA was performed using GraphPad Prism. Multiple comparison testing of dimethylsulfoxide (DMSO)-treated cells to indicated inhibitor reveals statistically significant suppression of cell growth as indicated by asterisks: ${ }^{* * *}, P<0.0001{ }^{*}{ }^{* *}, P<0.01$. (ns) Not significant.

To compare the relative potency and selectivity of dual PI3K/mTOR and AKT inhibitors observed in the PTEN/PI3KCA mutant OHSU-SARC0001 cell line to PTEN/PI3KCA wildtype cancer cell lines, we tested these inhibitors in three osteosarcoma cell lines (SJSA1, MG63, and HOS) that have no detectable aberrations in these genes (Supplemental Fig. 2). Although we would have preferred to test in PTEN/PI3KCA wild-type rhabdomyosarcoma cells, these models were not readily available to us for this study. These data show that the 
COLD SPRING HARBOR Molecular Case Studies
Targeted agents in spindle cell rhabdomyosarcoma

dual PI3K/mTOR inhibitor LY3023414 is generally cytotoxic in all cell lines we tested, independent on genomic status $\left(I_{50}\right.$ : OHSU-SARC001 $=0.02 \mu \mathrm{M} ;$ SJSA1 $=0.06 \mu \mathrm{M} ; \mathrm{MG} 63=$ $0.02 \mu \mathrm{M} ; \mathrm{HOS}=0.08 \mu \mathrm{M})$. The AKT inhibitors, afuresertib and ipatasertib, demonstrated modest cytotoxic effects in the osteosarcoma cells without PTEN or PI3KCA aberrations (Supplemental Fig. 2). However, the relative potency of afuresertib and ipatasertib is between 23- to 35-fold and six- to 16-fold greater in OHSU-SARC001 cells compared to wild-type PI3KCA/PTEN osteosarcoma cell lines, respectively.

\section{DISCUSSION}

Spindle cell/sclerosing rhabdomyosarcoma is a highly aggressive malignant skeletal muscle tumor, and patients with this diagnosis have poor clinical outcomes despite currently available standard-of-care interventions. The rarity of ssRMS and the lack of patient-derived cell lines are barriers to understanding tumor biology and expanding treatment options. To date, there have been only two ssRMS patient-derived cell lines (Schleicher et al. 2020; Yoshimatsu et al. 2020), and functional analyses in these rare tumors are limited. Here we provide data on OHSU-SARC001, a cell line derived from an ssRMS pediatric tumor specimen. NGS profiling identified a novel PIK3CA exon 9 deletion and a GNAS mutation, as well as a truncating

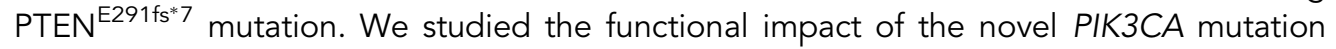
and also studied the influence of the GNAS mutation in tumor cells of this lineage. In addition, we explored the utility of molecularly targeting the PI3K/AKT/mTOR pathway that is activated in these cells via tailored drug testing.

Our data reveal that the novel PIK3CA ${ }^{1459}{ }^{\text {T462del }}$ deletion mutation induces constitutive catalytic activation of the kinase. Recent studies recognized coexistent PIK3CA mutations in MYOD1 L122R patients. Shukla et al. (2012) initially noted three of 60 embryonal rhabdomyosarcoma (ERMS) patients had PIK3CA E545L, E542K, or H1047R mutations. Since then, additional concurrent PIK3CA mutations have been reported. Agaram et al. (2019) found that 10 of 30 MYOD1-mutated ssRMS patients had concurrent PI3KCA exon 2 (K111E and K111del), exon 9 (E542K, E542V, E545A, E545K, and Q546R), and exon 20 (M1043V, H1047R, and G1049R) mutations that encompassed the kinase domain. Our study now identifies an additional PIK3CA mutation (1459_T462del), located in exon 9, as a potentially pathogenic variant. Crystal structure rendering of PIK3CA ${ }^{1459-T 462 d e l}$ provides a structural rationale supporting our biochemical findings; the 1459-T462 deletion resides at the interface of the PI3K catalytic and regulatory subunits and proximal to the established oncogenic PI3KCA ${ }^{\mathrm{E} 45}$ hotspot. One study investigated the clinical significance of PIK3CA in ssRMS outcomes; survival outcomes tended to be worse in cases with concurrent PIK3CA gain-of-function and MYOD1 mutation(s) versus cases that were WT PIK3CA, although findings were not statistically significant (Agaram et al. 2019). Conversely, another study noted a statistically significant worse outcome in patients with concurrent PIK3CA and MYOD1 mutations versus those with MYOD1 mutant alone (Wang et al. 2018). Additional investigations in ssRMS will shed light on the role of PIK3CA in oncogenesis in ssRMS, the potential of PI3K pathway-focused treatments, and the clinical impact of these mutations.

We found that OHSU-SARC001 has complete loss of PTEN protein. Our finding supports previous publications identifying concurrent PTEN loss in MYOD1-mutated ssRMS patients. In a study using targeted exome sequencing, PTEN deletions were noted in 2 of 10 patients (Agaram et al. 2019). In another study, two cases were noted to have PTEN deletions in addition to MYOD1 L122R (Kohsaka et al. 2014). Again, the prognostic significance of mutant PTEN compared to WT PTEN in MYOD1-mutated ssRMS patients is currently unknown, and further investigations are warranted as more cases are identified. 
The loss of PTEN ${ }^{\text {E291fs*7 }}$ in OHSU-SARC001 and the role of PIK3CA ${ }^{1459-T 462 d e l}$ as an activator of the mTOR/PI3K/AKT pathway suggested potential vulnerability to PIK3CA, AKT, and mTOR inhibitors. Susceptibility to targeted treatment involving the PI3K/AKT/mTOR pathway was supported by cell viability assays, in particular AKT inhibitors were relatively less effective in osteosarcoma cell lines (HOS, SJSA1, and MG63) that have wild-type PI3KCA and PTEN (Supplemental Fig. 2). AKT and dual mTOR/PIK3CA inhibitors could be beneficial in the setting of complex feedback loops in which inhibition of mTOR or PIK3CA can result in compensatory activation of the mTOR/PI3K pathway (Courtney et al. 2010). Adverse reactions and issues of tolerability with dual mTOR/PIK3CA and AKT inhibitors have been noted in several studies (Britten et al. 2014; Grabinski et al. 2014; Carlo et al. 2016; Powles et al. 2016). In addition, OHSU-SARC001 cells remain partially resistant to these molecularly targeted agents, as noted by their inability to achieve $100 \%$ killing in dose-response cell viability assays. These potential challenges may pose hurdles in translating our preclinical findings. However, the synergistic effects of dual mTOR/PIK3CA and AKT inhibitors in combination with other treatment options are unclear, and further studies are merited. Indeed, the effectiveness of combining treatment with IGF1R inhibitors and MEK inhibitor trametinib was shown to be more effective than single agent alone in a xenograft model of rhabdomyosarcoma (Yohe et al. 2018).

Another interesting observation in our studies was that although rapamycin and everolimus nearly completely suppressed p70S6K and S6 phosphorylation (key downstream effectors of mTOR), cell viability assays indicated growth-suppressive rather than dose-dependent cytotoxic effects. Single-agent mTOR inhibitors have been previously shown to induce cytostatic instead of cytotoxic effects (Easton and Houghton 2006; Faivre et al. 2006). Specifically, it was shown that mTOR inhibition induced $\mathrm{G}_{1}-\mathrm{S}$ arrest by decreasing cyclin $\mathrm{D} 1$ and increasing p27 expression (Hashemolhosseini et al. 1998). We observe a decrease in cyclin D1 levels in rapamycin and everolimus-treated SARC001 cells (Supplemental Fig. 3); however, no correlative increase in $\mathrm{p} 27 \mathrm{Kip} 1$ is observed. Further studies exploring the putative mechanisms governing this quiescent or cytostatic effect of mTOR inhibition in OHSU-SARC001 are indicated. Several theories including compensatory signaling pathways, epigenetic status, or mitochondrial priming are thought to contribute to lack of cytotoxicity (Yea and Fruman 2013). Interestingly, some tumors with PTEN loss have demonstrated susceptibility to mTOR inhibition (Podsypanina et al. 2001). In RMS, mTOR inhibition by rapamycin triggers a negative feedback mechanism resulting in the activation of AKT, which is dependent on IGF/IGF1R signaling (Wan et al. 2007). In vitro studies in RMS cells show that inhibition of IGF-1R with an antibody may be a putative strategy to block the AKT activation that occurs because of rapamycin-induced compensatory feedback pathways; these combination therapeutic strategies may enhance mTOR sensitivity (Wan et al. 2007; Cao et al. 2008).

Our data reveal that GNAS ${ }^{\mathrm{R} 201 \mathrm{C}}$ does not enhance the MEK/ERK pathway signaling as compared to wild-type GNAS in C2C12, murine myoblast lineage cells, and, correlatively, MEK inhibitors had no effect on OHSU-SARC001 viability. Thus, the GNAS ${ }^{\text {R201C }}$ alteration may drive other pathways dependent on CAMP, such as metabolic pathways. Correspondingly, an in vivo colorectal murine study found that GNAS ${ }^{\mathrm{R} 201 \mathrm{C}}$ alone was insufficient to generate tumors. However, when crossbred to express APC inactivation and GNAS ${ }^{\text {2201C }}$, mice developed a twofold increase in adenomas (Wilson et al. 2010). GNAS $^{\text {R201C }}$ in our ssRMS model may act in a similar cooperative fashion with the other oncogenic aberrations that we did not fully recapitulate in our model system. Additionally, combination treatments involving MEK/ERK inhibitors may be necessary in order to result in cell death. Notably, MAPK and mTOR/AKT pathways appear to intersect and coregulate downstream functions with forkhead box transcription factor class $\mathrm{O}$ (FOXO), BCL-2 associated death promoter (BAD), and glycogen synthase kinase 3 (GSK3) (Mendoza et al. 2011). This cross talk could therefore limit the efficacy of single-agent inhibitors. In rhabdomyosarcoma, 
COLD SPRING HARBOR Molecular Case Studies
Targeted agents in spindle cell rhabdomyosarcoma synergistic lethal effects occurred when combining PI3K/mTOR and MEK inhibitors, whereas single agents induced minimal cell death (Guenther et al. 2013). These studies may provide rationale for testing MAPK and PIK3CA/mTOR inhibitor combinations in ssRMS.

A limitation in our cell viability assays is that we did not test standard-of-care chemotherapy agents. Given that ssRMS patients are often resistant to standard chemotherapy, we sought to focus efforts in precision medicine strategies, as pediatric patients may benefit from less toxic therapies. However, with the notable susceptibility to AKT and mTOR/AKT inhibitors, future investigations into potential synergistic effects of chemotherapy in combination with targeted treatments are indicated.

The rarity of patients with ssRMS and the lack of preclinical ssRMS models pose a challenge to understanding the tumor biology and susceptibility to targeted treatments. With the development of a validated, pediatric patient-derived ssRMS cell line, we now have an opportunity for further preclinical investigations. This is the initial step in advancing knowledge of pediatric ssRMS tumor biology, potentially leading to future clinical trials.

\section{METHODS}

\section{Generation of Patient-Derived Cell Line}

Patient consent was obtained per an institutional review board-approved biological specimen collection protocol (IRB\#4918). Tissue samples were collected and minced in Dulbecco's modified Eagle's medium (DMEM):F12, 2\% (v/v) fetal bovine serum (FBS), 1\% $(\mathrm{v} / \mathrm{v})$ glutamax, $1 \%(\mathrm{v} / \mathrm{v})$ sodium pyruvate, $1 \%(\mathrm{v} / \mathrm{v})$ penicillin and streptomycin, and $0.5 \%$ $(\mathrm{v} / \mathrm{v})$ fungizone. The tumor underwent collagenase IV treatment for 25 min while shaken at $37^{\circ} \mathrm{C}$. D10 with $10 \%$ fetal bovine serum (FBS) was added to neutralize the reaction. The sample was spun down at $200 \mathrm{~g}$ for $5 \mathrm{~min}$, and cells were counted via hemocytometer and seeded in T25 flasks in DMEM:F12 supplemented with 10\% (v/v) FBS, 1\% (v/v) penicillin and streptomycin, and $0.5 \%(\mathrm{v} / \mathrm{v})$ fungizone. The initial culture expanded and the first passage of cells was frozen and cryopreserved using BAMBANKER medium.

\section{Validation of Patient-Derived Cell Line Using Next-Generation Sequencing}

Genomic DNA from OHSU-SARC001 was extracted usinga PureLink Genomic DNA Kit (Invitrogen) following the manufacturer's guidelines. An amount of 10 ng of gDNA was submitted to the Knight Diagnostic Laboratories, a CLIA-licensed and College of American Pathologists (CAP)-certified laboratory, for GeneTrails Comprehensive Solid Tumor Panel. Tumor-rich regions of FFPE sections of tissue were macrodissected and deparaffinized, and total nucleic acid was extracted and purified using the NucleoSpin Tissue kit (Machery-Nagel). Amplicon-based sequencing libraries (custom QIAseq panel, QIAGEN) covering the protein coding regions of 124 cancer-related genes (Mitri et al. 2018) were prepared from tumor DNA samples and sequenced on an Illumina NextSeq550. Sequence alignment and variant calls were determined using a CLIA-validated pipeline.

\section{Cell Lines}

OHSU-SARC001 cells were grown in a humidified incubator under $5 \% \mathrm{CO}_{2}$ at $37^{\circ} \mathrm{C}$ and cultured using DMEM:F12 supplemented with 10\% (v/v) FBS, 1\% (v/v) L-glutamine, 1\% (v/v) penicillin/streptomycin, and $0.5 \%(\mathrm{v} / \mathrm{v})$ fungizone. $\mathrm{C} 2 \mathrm{C} 12$ cells were purchased from the American Type Culture Collection (CRL-1772). U2OS, C2C12, and C2C12 stable cell lines were cultured in D10 supplemented with 10\% (v/v) FBS, 1\% (v/v) L-glutamine, 1\% (v/v) penicillin/streptomycin, and $0.5 \%$ (v/v) fungizone. 
Site-Directed Mutagenesis

pDONR223-PIK3CA and pDONR221-GNAS were purchased from Addgene and DNASU, respectively. PIK3CA WT, PIK3CA ${ }^{1459-T 462 d e l}$, GNAS WT, and GNAS ${ }^{\text {R201C }}$ mutants were generated using site-directed mutagenesis (primers listed in Supplemental Table 2) following manufacturer's guidelines (Agilent) and verified via sequencing. PIK3CA ${ }^{\mathrm{E} 545}$, GNAS WT in addition to PIK3CA WT, PIK3CA ${ }^{1459}$-T462del, and GNAS ${ }^{\text {2201C }}$ plasmids were propagated using Stellar competent cells (Clontech) and were processed using QIAprep Spin Miniprep Kit (QIAGEN) per manufacture guidelines. All PIK3CA and GNAS plasmids were inserted into destination vector pCX4-puro using Gateway LR Clonase II enzyme mix (Invitrogen) following manufacturer's instructions. A previously described and validated MYOD1 L122R plasmid with a pCX4-zeocin-containing vector was used (Kohsaka et al. 2014). Samples were miniprepped using QIAprep Spin Miniprep Kit (QIAGEN) following manufacturer's directions.

Generation of Incompetent Infectious Ecotropic Retroviral Particles and Transduction of $\mathrm{C} 2 \mathrm{C} 12$ Stable Cell Lines

Platinum E-cells (Cell Biolabs, Inc.) were transfected in six-well plates using $4 \mu \mathrm{g}$ of puromycin-selectable pCX4-pur retroviral vectors harboring PIK3CA WT, PIK3CA ${ }^{\mathrm{E} 545 \mathrm{~K}}$,

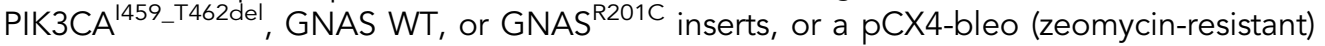
MYOD L122R insert using DNA transfection reagent from BioTool to generate replicationincompetent, ecotropic retrovirus. After $48 \mathrm{~h}, 60 \%$ confluent $\mathrm{C} 2 \mathrm{C} 12$ cells were transduced with retroviral particle-containing culture supernatants. PIK3CA-transduced cell lines were selected using $0.5 \mu \mathrm{g} / \mathrm{mL}$ puromycin (InvivoGen), GNAS-transduced cell lines underwent selection with $1 \mu \mathrm{g} / \mathrm{mL}$ puromycin (InvivoGen), and MYOD1 with $750 \mu \mathrm{g} / \mathrm{mL}$ zeocin (InvivoGen). Cell lines were selected with the respective antibiotics for $14 \mathrm{~d}$.

\section{Sanger Sequencing for Validation of C2C12 Stable Cell Lines}

Stable cell lines were validated using Sanger sequencing of polymerase chain reaction (PCR)amplified genomic DNA (Supplemental Table 2). Specifically, for genomic DNA isolation, phosphate-buffered saline (PBS)-washed cell line pellets were mixed with QuickExtra DNA extraction solution (Lucigen) and incubated as follows: $10 \mathrm{~min}$ at $68^{\circ} \mathrm{C}$, followed by $15 \mathrm{~min}$ at $95^{\circ} \mathrm{C}$. PCR amplification of regions of interest was performed using BestTaq (Applied Biological Materials Inc.) with respective primer sets (Supplemental Table 2). PCR samples were cleaned on DNA Clean \& Concentrator-25 (Zymo Research) columns and submitted for Sanger sequencing. GNAS, PIK3CA WT, PIK3CA ${ }^{\mathrm{E} 545}$, PIK3CA ${ }^{1459-T 462 d e l}$, GNAS WT, and GNAS $^{\mathrm{R} 201 \mathrm{C}}$ mutations were confirmed with sequencing primers indicated in Supplemental Table 2.

\section{OHSU-SARC001 PDX Mouse Model}

Mice were cared for per the Memorial Sloan Kettering Cancer Center Institutional Animal Care and Use Committee and Research Animal Resource Center. OHSU-SARC001 cells were trypsinized and counted per hemocytometer. The $5 \times 10^{6}$ OHSU-SARC001 cells were pelleted and resuspended in PBS. The PBS mixture was mixed 1:1 with Matrigel (Corning) and injected subcutaneously into a flank of a 6-wk-old female NSG mouse. Tumor growth was assessed weekly, and tumor volume was calculated using volume $\times$ length $\times$ width $^{2} \times 0.52$. Tumors were serially transplanted three times.

\section{Histology and Immunohistochemistry}

Slides were H\&E-stained, and immunohistochemistry was performed on FFPE tissues using standard protocols and immunoperoxidase techniques with appropriate controls. H\&E 
COLD SPRING HARBOR Molecular Case Studies
Targeted agents in spindle cell rhabdomyosarcoma slides from the mouse PDX tissue were compared to the original patient tumor. Antibodies used to evaluate both the primary patient tumor and PDX are described in Supplemental Table 1. MYOD1 staining was completed by PhenoPath Laboratories.

\section{Immunoblotting}

For Akt/mTOR signaling assessments, C2C12 PIK3CA ${ }^{\mathrm{E} 545}, \mathrm{C} 2 \mathrm{C} 12$ PIK3CA WT, C2C12

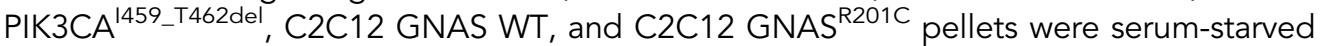
for $6 \mathrm{~h}$. For characterization of the drug effect on SARC001 and the Akt/mTOR- and ERK-signaling pathways, drugs LY3023414 (MedChemExpress), trametinib (Selleckchem), everolimus (Selleckchem), bimiralisib (Cayman Chemical), and rapamycin (Selleckchem) were used at concentrations of 50 and $250 \mathrm{nM}$ (diluted with dimethylsulfoxide [DMSO]) for 24 h. Cell pellets were lysed in $200 \mu \mathrm{L}$ cell lysis buffer (Cell Signaling Technologies [CST]) supplemented with $0.25 \%$ deoxycholate, $0.05 \%$ sodium dodecyl sulfate (SDS), and protease and phosphatase inhibitors (BioTool). Protein concentrations were assessed using the Pierce BCA Protein assay kit (ThermoFisher Scientific). Protein was denatured using $1 \times$ NuPAGE LDS Sample Buffer (Invitrogen) for $10 \mathrm{~min}$ at $75^{\circ} \mathrm{C}$. Samples were loaded into Bolt 4\%-12\% Bis-Tris Plus gels (Fisher Scientific) with MOPS or MES buffers. Proteins were transferred onto nitrocellulose membranes (Prometheus) and probed for the following antibodies: phospho-Akt (Ser473) (D9E) (4060S, 1:1000; CST), phospho-Akt (Thr308) (244F9) (4056S, 1:1000; CST), total Akt (40D4) (2920S, 1:1000; CST), phospho-mTOR (Ser2448 ([5536S, 1:2000; CST), total mTOR (7C10) (2983, 1:1000; CST), phospho-p44/42 MAPK (T202/Y204) (9101, 1:1000; CST), total p44/42 MAPK (ERK 2) (D-2) (sc-1647, 1:1000; Santa Cruz Biotechnology), phospho-4EBP1 (T37/46)(236B4) (2855S, 1:1000; CST), total 4EBP1 (53H11) (9644, 1:1000; CST), phospho-tuberin/TSC2 (Thr1462)(5B12) (3617S, 1:1000; CST), total-tuberin/TSC2 (3612S, 1:1000; CST), phospho-S6 (S235/236) (D57.2.E) (4858S, 1:1000; CST), total - S6 (54D2) (2317S, 1:1000; CST), phospho-elF4E (S209) (9741, 1:1000; CST), phospho- p70 S6 Kinase (Thr389) (9205, 1:1000; CST), phospho-p70 S6 Kinase (Thr421 and S424) (A5033, 1:1000; Bimake) phospho-B-Raf (F-7) (sc-5284, 1:1000; Santa Cruz Biotechnology), phospho-c-Raf (D4B3J) (9422S, 1:1000, CST), phospho rap-1B (36E1) (2326S, 1:1000; CST), PTEN (A5040, 1:1000; Bimake), cyclin D1 (A5035, 1:1000; Bimake), p27 kip1 (3698, 1:1000; CST), a-tubulin (EP1332Y) (52866, 1:1000; Abcam) GAPDH (14C10) (2118S, 1:5000; CST), and actin (JLA-20, 1:5000; DSHB). Blots were imaged using a Bio-Rad ChemiDoc imaging station (per manufacturer's protocol using horseradish peroxidase-conjugated secondary antibodies) or Odyssey CLx using fluorescent secondary antibodies.

\section{Drug Dose-Reponses Curves}

Between 1500 and 2000 cells per well of Plat-E, U2OS, SJSA1, HOS, and MG63 were seeded in a 384-well plate using a Multidrop Combi Reagent Dispenser (ThermoFisher Scientific) in $25 \mu \mathrm{L}$ of media. Six thousand OHSU-SARC001 cells per well were seeded in a 96-well plate manually. Plat-E, U2OS, SJSA1, HOS, and MG63 were seeded using D10 media, whereas OHSU-SARC001 was seeded using DMEM:F12. Cells were cultured for 3-5 d depending on doubling time. Inhibitors (LY3023414, everolimus, bimiralisib, rapamycin, trametinib, doxorubicin [Selleckchem], vincristine [MedChemExpress)], actinomycin [MedChemExpress], DMSO, and staurosporine [Selleckchem]) were added using a D300 Digital Dispenser (Hewlett-Packard) ranging from 0.001 to $10 \mu \mathrm{M}$. Dose-response assays involving ipatasertib and afuresertib (MedChemExpress) with ranges of 0.001 to $10 \mu \mathrm{M}$ were added manually to 96-well plates. Plat-E-, U2OS-, SJSA-, HOS-, and MG63-containing plates were incubated for $72 \mathrm{~h}$ at $37^{\circ} \mathrm{C}$ and $5 \% \mathrm{CO}_{2}$. OHSU-SARC001 cells were incubated for $6 \mathrm{~d}$ 
Competing Interest Statement The authors have declared no competing interest.

Referees

Patience Obasaju

Anonymous

Received August 5, 2021; accepted in revised form December 6, 2021. (given slow doubling time) at $37^{\circ} \mathrm{C}, 5 \% \mathrm{CO}_{2}$. Viability was measured using a Cell Counting Kit-8 (Bimake) and read on a Biotek Synergy 2 plate reader.

\section{Statistics and Reproducibility}

In vitro studies represent three independent experiments with triplicate samples for reproducibility and rigor. Dose-response data was normalized and analyzed using Microsoft Excel and GraphPad Prism to determine 50\% growth inhibitory concentration $\left(\mathrm{IC}_{50}\right)$ using a nonlinear curve fit equation. Statistical analysis with two-way ANOVA was performed using Graphpad Prism.

\section{ADDITIONAL INFORMATION}

\section{Data Deposition and Access}

The PIK3CA ${ }^{1459-T 462 d e l}$ variant has been submitted to ClinVar (https://www.ncbi.nlm.nih .gov/clinvar) and can be found accession number VCV001327587.1. Additional information is available from the corresponding author upon request.

\section{Ethics Statement}

Patient consent was obtained per Oregon Health \& Science University Institutional Review Board-approved bio specimen collection protocol (IRB\#4918).

\section{Acknowledgments}

We are thankful to the patient and his family for their participation in this study and the support from the Division of Pediatric Hematology Oncology at Doernbecher Children's Hospital.

\section{Author Contributions}

F.C., M.D., and L.S. conceptualized the design of the study. F.C., K.N., and K.S.N. conducted in vitro investigations and I.O., R.S., and M.L. conducted in vivo experiments. J.L.D. provided pathologic review of the study. C.L.C. generated the GeneTrails data on OSHU-SARC001 and performed data interpretation and analysis. F.C., M.A.D., L.D., M.L., and R.S. analyzed data. F.C., M.A.D., I.O., and R.S. wrote and edited the manuscript. All authors reviewed, contributed to, and approved the final manuscript.

\section{Funding}

This research was supported by funds from the Oregon Health \& Science University, Department of Pediatrics, Division of Pediatric Hematology Oncology, a grant from Cycle For Survival to M.L., and a Cancer Center Support Grant (P30 CA008748) to Memorial Sloan Kettering Cancer Center.

\section{REFERENCES}

Agaram NP, LaQuaglia MP, Alaggio R, Zhang L, Fujisawa Y, Ladanyi M, Wexler LH, Antonescu CR. 2019. MYOD1-mutant spindle cell and sclerosing rhabdomyosarcoma: an aggressive subtype irrespective of age. A reappraisal for molecular classification and risk stratification. Mod Pathol 32: 27-36. doi:10.1038/ s41379-018-0120-9 
Amer KM, Thomson JE, Congiusta D, Dobitsch A, Chaudhry A, Li M, Chaudhry A, Bozzo A, Siracuse B, Aytekin $\mathrm{MN}$, et al. 2019. Epidemiology, incidence, and survival of rhabdomyosarcoma subtypes: SEER and ICES database analysis. J Orthop Res 37: 2226-2230. doi:10.1002/jor.24387

Britten CD, Adjei AA, Millham R, Houk BE, Borzillo G, Pierce K, Wainberg ZA, LoRusso PM. 2014. Phase I study of PF-04691502, a small-molecule, oral, dual inhibitor of PI3K and mTOR, in patients with advanced cancer. Invest New Drugs 32: 510-517. doi:10.1007/s10637-013-0062-5

Cao L, Yu Y, Darko I, Currier D, Mayeenuddin LH, Wan X, Khanna C, Helman LJ. 2008. Addiction to elevated insulin-like growth factor I receptor and initial modulation of the AKT pathway define the responsiveness of rhabdomyosarcoma to the targeting antibody. Cancer Res 68: 8039-8048. doi:10.1158/0008-5472.CAN08-1712

Carlo MI, Molina AM, Lakhman Y, Patil S, Woo K, DeLuca J, Lee CH, Hsieh JJ, Feldman DR, Motzer RJ, et al. 2016. A phase Ib study of BEZ235, a dual inhibitor of phosphatidylinositol 3-kinase (PI3K) and mammalian target of rapamycin (mTOR), in patients with advanced renal cell carcinoma. Oncologist 21: 787-788. doi:10.1634/theoncologist.2016-0145

Cavazzana AO, Schmidt D, Ninfo V, Harms D, Tollot M, Carli M, Treuner J, Betto R, Salviati G. 1992. Spindle cell rhabdomyosarcoma. A prognostically favorable variant of rhabdomyosarcoma. Am J Surg Pathol 16: 229-235. doi:10.1097/00000478-199203000-00002

Courtney KD, Corcoran RB, Engelman JA. 2010. The PI3K pathway as drug target in human cancer. J Clin Oncol 28: 1075-1083. doi:10.1200/JCO.2009.25.3641

Cyrta J, Gauthier A, Karanian M, Vieira AF, Cardoen L, Jehanno N, Bouvet M, Bouvier C, Komuta M, Le Loarer $F$, et al. 2021. Infantile rhabdomyosarcomas with VGLL2 rearrangement are not always an indolent disease: a study of 4 aggressive cases with clinical, pathologic, molecular, and radiologic findings. Am J Surg Pathol 45: 854-867. doi:10.1097/pas.0000000000001702

Easton JB, Houghton PJ. 2006. mTOR and cancer therapy. Oncogene 25: 6436-6446. doi:10.1038/sj.onc 1209886

Faivre S, Kroemer G, Raymond E. 2006. Current development of mTOR inhibitors as anticancer agents. Nat Rev Drug Discov 5: 671-688. doi:10.1038/nrd2062

Grabinski N, Möllmann K, Milde-Langosch K, Müller V, Schumacher U, Brandt B, Pantel K, Jücker M. 2014. AKT3 regulates ErbB2, ErbB3 and estrogen receptor a expression and contributes to endocrine therapy resistance of ErbB2 ${ }^{+}$breast tumor cells from Balb-neuT mice. Cell Signal 26: 1021-1029. doi:10.1016/j .cellsig.2014.01.018

Guenther MK, Graab U, Fulda S. 2013. Synthetic lethal interaction between PI3K/Akt/mTOR and Ras/MEK/ERK pathway inhibition in rhabdomyosarcoma. Cancer Lett 337: 200-209. doi:10.1016/j.canlet.2013.05.010

Hashemolhosseini S, Nagamine Y, Morley SJ, Desrivières S, Mercep L, Ferrari S. 1998. Rapamycin inhibition of the $\mathrm{G} 1$ to $\mathrm{S}$ transition is mediated by effects on cyclin D1 mRNA and protein stability. J Biol Chem 273: 14424-14429. doi:10.1074/jbc.273.23.14424

Jo V, Fletcher C. 2014. WHO classification of soft tissue tumours: an update based on the 2013 (4th) edition. Pathology 46: 95-104.

Kikuchi K, Wettach GR, Ryan CW, Hung A, Hooper JE, Beadling C, Warrick A, Corless CL, Olson SB, Keller C, et al. 2013. MDM2 amplification and PI3KCA mutation in a case of sclerosing rhabdomyosarcoma. Sarcoma 2013: 520858. doi:10.1155/2013/520858

Kohsaka S, Shukla N, Ameur N, Ito T, Ng CK, Wang L, Lim D, Marchetti A, Viale A, Pirun M, et al. 2014. A recurrent neomorphic mutation in MYOD1 defines a clinically aggressive subset of embryonal rhabdomyosarcoma associated with PI3K-AKT pathway mutations. Nat Genet 46: 595-600. doi:10.1038/ng.2969

Leuschner I, Newton WA Jr, Schmidt D, Sachs N, Asmar L, Hamoudi A, Harms D, Maurer HM. 1993. Spindle cell variants of embryonal rhabdomyosarcoma in the paratesticular region. A report of the Intergroup Rhabdomyosarcoma Study. Am J Surg Pathol 17: 221-230. doi:10.1097/00000478-199303000-00002

Maione R, Amati P. 1997. Interdependence between muscle differentiation and cell-cycle control. Biochim Biophys Acta 1332: M19-M30. doi:10.1016/s0304-419x(96)00036-4

Mendoza MC, Er EE, Blenis J. 2011. The Ras-ERK and PI3K-mTOR pathways: cross-talk and compensation. Trends Biochem Sci 36: 320-328. doi:10.1016/j.tibs.2011.03.006

Mitri ZI, Parmar S, Johnson B, Kolodzie A, Keck JM, Morris M, Guimaraes AR, Beckett BR, Borate U, Lopez CD, et al. 2018. Implementing a comprehensive translational oncology platform: from molecular testing to actionability. J Transl Med 16: 358. doi:10.1186/s12967-018-1733-y

Newton WA Jr, Gehan EA, Webber BL, Marsden HB, van Unnik AJ, Hamoudi AB, Tsokos MG, Shimada H, Harms D, Schmidt D, et al. 1995. Classification of rhabdomyosarcomas and related sarcomas. Pathologic aspects and proposal for a new classification-an Intergroup Rhabdomyosarcoma Study. Cancer 76: 1073-1085. doi:10.1002/1097-0142(19950915)76:6 \&lt; 1073::aid-cncr2820760624 > 3.0.co ;2-I

Ognjanovic S, Linabery AM, Charbonneau B, Ross JA. 2009. Trends in childhood rhabdomyosarcoma incidence and survival in the United States, 1975-2005. Cancer 115: 4218-4226. doi:10.1002/cncr.24465 
Owens J, Moreira K, Bain G. 2013. Characterization of primary human skeletal muscle cells from multiple commercial sources. In Vitro Cell Dev Biol Anim 49: 695-705. doi:10.1007/s11626-013-9655-8

Podsypanina K, Lee RT, Politis C, Hennessy I, Crane A, Puc J, Neshat M, Wang H, Yang L, Gibbons J, et al. 2001. An inhibitor of mTOR reduces neoplasia and normalizes p70/S6 kinase activity in Pten ${ }^{+/-}$mice. Proc Natl Acad Sci 98: 10320-10325. doi:10.1073/pnas.171060098

Powles T, Lackner MR, Oudard S, Escudier B, Ralph C, Brown JE, Hawkins RE, Castellano D, Rini BI, Staehler MD, et al. 2016. Randomized open-label phase II trial of apitolisib (GDC-0980), a novel inhibitor of the $\mathrm{PI} 3 \mathrm{~K} / \mathrm{mammalian}$ target of rapamycin pathway, versus everolimus in patients with metastatic renal cell carcinoma. J Clin Oncol 34: 1660-1668. doi:10.1200/jco.2015.64.8808

Rudzinski ER, Anderson JR, Hawkins DS, Skapek SX, Parham DM, Teot LA. 2015. The World Health Organization classification of skeletal muscle tumors in pediatric rhabdomyosarcoma: a report from the Children's Oncology Group. Arch Pathol Lab Med 139: 1281-1287. doi:10.5858/arpa.2014-0475-OA

Schleicher S, Grote S, Malenke E, Chan KC, Schaller M, Fehrenbacher B, Riester R, Kluba T, Frauenfeld L, Boesmueller $\mathrm{H}$, et al. 2020. Establishment and characterization of a sclerosing spindle cell rhabdomyosarcoma cell line with a complex genomic profile. Cells 9: 2668. doi:10.3390/cells9122668

Shern JF, Selfe J, Izquierdo E, Patidar R, Chou HC, Song YK, Yohe ME, Sindiri S, Wei J, Wen X, et al. 2021. Genomic classification and clinical outcome in rhabdomyosarcoma: a report from an international consortium. J Clin Oncol 39: 2859-2871. doi:10.1200/JCO.20.03060

Shukla N, Ameur N, Yilmaz I, Nafa K, Lau CY, Marchetti A, Borsu L, Barr FG, Ladanyi M. 2012. Oncogene mutation profiling of pediatric solid tumors reveals significant subsets of embryonal rhabdomyosarcoma and neuroblastoma with mutated genes in growth signaling pathways. Clin Cancer Res 18: 748-757. doi:10 .1158/1078-0432.Ccr-11-2056

Sorrentino V, Pepperkok R, Davis RL, Ansorge W, Philipson L. 1990. Cell proliferation inhibited by MyoD1 independently of myogenic differentiation. Nature 345: 813-815. doi:10.1038/345813a0

Stork PJS, Schmitt JM. 2002. Crosstalk between cAMP and MAP kinase signaling in the regulation of cell proliferation. Trends Cell Biol 12: 258-266. doi:10.1016/S0962-8924(02)02294-8

Tsai JW, ChangChien YC, Lee JC, Kao YC, Li WS, Liang CW, Liao IC, Chang YM, Wang JC, Tsao CF, et al. 2019. The expanding morphological and genetic spectrum of MYOD1-mutant spindle cell/sclerosing rhabdomyosarcomas: a clinicopathological and molecular comparison of mutated and non-mutated cases. Histopathology 74: 933-943. doi:10.1111/his.13819

Van Antwerp ME, Chen DG, Chang C, Prochownik EV. 1992. A point mutation in the MyoD basic domain imparts c-Myc-like properties. Proc Natl Acad Sci 89: 9010-9014. doi:10.1073/pnas.89.19.9010

Wan X, Harkavy B, Shen N, Grohar P, Helman LJ. 2007. Rapamycin induces feedback activation of Akt signaling through an IGF-1R-dependent mechanism. Oncogene 26: 1932-1940. doi:10.1038/sj.onc.1209990

Wang Y, Li J, Tian Z, Zhu Y. 2018. Clinicopathologic features and molecular spectrum of spindle cell and sclerosing rhabdomyosarcomas in the head and neck region. Int J Clin Exp Pathol 11: 3436-3444.

Weintraub H. 1993. The MyoD family and myogenesis: redundancy, networks, and thresholds. Cell 75: $1241-$ 1244. doi:10.1016/0092-8674(93)90610-3

Wilson CH, Mclntyre RE, Arends MJ, Adams DJ. 2010. The activating mutation R201C in GNAS promotes intestinal tumourigenesis in $\mathrm{Apc}^{\mathrm{Min} /+}$ mice through activation of Wnt and ERK1/2 MAPK pathways. Oncogene 29: 4567-4575. doi:10.1038/onc.2010.202

World Health Organization. 2020. Soft tissue and bone tumours: WHO classification of tumours, 5th ed. International Agency for Research on Cancer, Lyon, France.

Yea SS, Fruman DA. 2013. Achieving cancer cell death with PI3K/mTOR-targeted therapies. Ann NY Acad Sci 1280: 15-18. doi:10.1111/nyas. 12028

Yohe ME, Gryder BE, Shern JF, Song YK, Chou HC, Sindiri S, Mendoza A, Patidar R, Zhang X, Guha R, et al. 2018. MEK inhibition induces MYOG and remodels super-enhancers in RAS-driven rhabdomyosarcoma. Sci Transl Med 10: eaan4470. doi:10.1126/scitranslmed.aan4470

Yoshimatsu Y, Noguchi R, Tsuchiya R, Sei A, Sugaya J, Iwata S, Sugiyama M, Yoshida A, Kawai A, Kondo T. 2020. Establishment and characterization of NCC-ssRMS1-C1: a novel patient-derived spindle-cell/sclerosing rhabdomyosarcoma cell line. Hum Cell 33: 886-893. doi:10.1007/s13577-020-00359-1

Zhang Y, Kwok-Shing Ng P, Kucherlapati M, Chen F, Liu Y, Tsang YH, de Velasco G, Jeong KJ, Akbani R Hadjipanayis A, et al. 2017. A pan-cancer proteogenomic atlas of PI3K/AKT/mTOR pathway alterations. Cancer Cell 31: 820-832.e823. doi:10.1016/j.ccell.2017.04.013 


\section{COLD SPRING HARBOR Molecular Case Studies}

\section{Functional impact and targetability of PI3KCA, GNAS, and PTEN mutations in a spindle cell rhabdomyosarcoma with MYOD1 L122R mutation}

Florence Choo, Igor Odintsov, Kevin Nusser, et al.

Cold Spring Harb Mol Case Stud 2022, 8: a006140

Access the most recent version at doi: $10.1101 / \mathrm{mcs} . \mathrm{a} 006140$

Supplementary http://molecularcasestudies.cshlp.org/content/suppl/2022/01/05/mcs.a006140.D
Material

References This article cites 41 articles, 9 of which can be accessed free at:

http://molecularcasestudies.cshlp.org/content/8/1/a006140.full.html\#ref-list-1

License This article is distributed under the terms of the Creative Commons Attribution-NonCommercial License, which permits reuse and redistribution, except for commercial purposes, provided that the original author and source are credited.

Email Alerting Receive free email alerts when new articles cite this article - sign up in the box at the Service top right corner of the article or click here. 